\title{
Lithological Mapping Using Landsat 8 OLI in the Meso-Cenozoic Tarfaya Laayoune Basin (South of Morocco): Comparison between ANN and SID Classification
}

\author{
Amine Bouwafoud, Mustapha Mouflih, Abdelmajid Benbouziane \\ Hassan II University of Casablanca, Faculty of Sciences Ben M’sik, Geosciences and Application Laboratory (LGA), Sidi Othmane, \\ Casablanca, Morocco \\ Email: amine.bouwafoud-etu@etu.univh2c.ma
}

How to cite this paper: Bouwafoud, A., Mouflih, M. and Benbouziane, A. (2021) Lithological Mapping Using Landsat 8 OLI in the Meso-Cenozoic Tarfaya Laayoune Basin (South of Morocco): Comparison between ANN and SID Classification. Open Journal of Geology, 11, 658-681.

https://doi.org/10.4236/ojg.2021.1112032

Received: November 11, 2021

Accepted: December 17, 2021

Published: December 20, 2021

Copyright $\odot 2021$ by author(s) and Scientific Research Publishing Inc. This work is licensed under the Creative Commons Attribution International License (CC BY 4.0).

http://creativecommons.org/licenses/by/4.0/

(c) (i) Open Access

\begin{abstract}
In the Saharian domain, the Tarfaya-Laayoune coastal basin developed in a stable passive margin, where asymmetrical sedimentation increase from East to West and reach a sediment stack of about 14 kilometers. However, the morphology of the studied area corresponds to a vast plateau (hamada) presenting occasional major reliefs. For this purpose, remote sensing approach has been applied to find the best approaches for truthful lithological mapping. The two supervised classification methods by machine learning (Artificial Neural Network and Spectral Information Divergence) have been evaluated for a most accurate classification to be used for our lithofacies mapping. The latest geological maps and RGB images were used for pseudo-color groups to identify important areas and collect the ROIs that will serve as facilities samples for the classifications. The results obtained showed a clear distinction between the various formation units, and very close results to the field reality in the ANN classification of the studied area. Thus, the ANN method is more accurate with an overall accuracy of $92.56 \%$ and a Kappa coefficient is 0.9143 .
\end{abstract}

\section{Keywords}

Tarfaya-Laayoune Basin, Geological Mapping, Supervised Classification, Artificial Neural Network, Spectral Information Divergence

\section{Introduction}

Orbital technology is continuously improving advanced levels which are useful for lithologic mapping as well as mineral exploration [1]-[13]. 
Advances in image classification and the ability to integrate multiple data sources have further improved geological surveys using remote sensing technologies. There are a multitude of classification algorithms that have proven to be effective in geological mapping: Artificial Neural Networks (ANN) [14]-[21], Spectral Angle Mapper (SAM) [13] [15] [22] [23] [24] [25], Support Vector Machines (SVM) [13] [26] [27] [28] [29].

On the other hand, advances in Landsat sensors with two additional spectral bands and a narrower bandwidth are an advantage for applications requiring thinner, narrow bands, as well the development of spectral indices for various applications of Landsat data, including agriculture, land cover mapping, cool and coastal water mapping, snow and ice, soil and geology [30]. In this sense, Landsat bands are well-known for particular applications: band 7 (geological band), band 5 (soil and rock discrimination) and band 3 (soil/vegetation discrimination) [31] [32] [33].

The Meso-Cenozoic Tarfaya-Laayoune-Dakhla basin is located NW of the Archean-Proterozoic ridge of Réguibate, NW of the West African craton. The studied region belongs to the Tarfaya-Laayoune basin, the central region of the Meso-Cenozoic Tarfaya-Laayoune-Dakhla basin, which has been a relatively stable tectonic platform since the Jurassic period [34]. Primarily, the Meso-Cenozoic formations mainly arbitrate layers of bituminous, phosphate and limestone rocks of obvious economic interest.

Like all arid regions, the geological mapping is more complicated because most of the formations are invaded by large movements of sand $(34 \mathrm{~m} / \mathrm{s})$ accelerated by the flat morphology of the land [35]. However, the geological mapping coverage has been reported by several maps at a scale of 1:100.000 and which concern the type-localities (from the North to the South): Tarfaya, Tah, Oum Debaa and Laayoune [34].

In another sense, this work aims to classify lithofacies by processing Landsat 8 multispectral data. Artificial Neural Network (ANN) and Spectral Information Divergence (SID) were used for classification while the spectra of the regions of interest (ROI) of the image were used as end members. For better precision, The ANN and SID classifiers were compared, and a choice was made for the classifier to be used as a support for geological mapping. Finally, we are guided to make a comparison between the two classification methods to choose the most efficient for a good presentation of the lithological cartography of the area.

\section{Geological Settings}

In Morocco, the Saharan domain presents morphological, climatic and hydrological peculiarities. This area is characterized by arid conditions, precipitation less than $54 \mathrm{~mm} /$ year, an annual average temperature that varies between $17^{\circ} \mathrm{C}$ on the coast and $25^{\circ} \mathrm{C}$ elsewhere and 3239.81 hours of sunshine per year. This domain is established on Precambrian crystalline lands (climate-data.org).

The Tarfaya-Laayoune-Dakhla (Figure 1) basin is part of the western margin 
of the platform. It is made up of a set of elongated NE-SW basins, parallel to the coast [34] [36]. These basins are from $\mathrm{N}$ to S: Tarfaya-Laayoune, Boujdour, Dakhla, Lagwira. They were formed during the Mesozoic and Cenozoic in the marine direction of the Archean-Proterozoic formations of the Reguibate Ridge and the folded Paleozoic sediments of the Paleozoic basin of Tindouf.

The Tarfaya Laayoune basin is separated from the Essouira-Agadir basin by the stable structural top of the Anti-Atlas. It is limited to the N and NE, successively, by the anti-Atlas Proterozoic domain and the Paleozoic-Cenozoic basin of Tindouf, to the E by the Archean and Proterozoic crystalline massif of the Tiris domain and to the SE and S by the Archean and Proterozoic crystalline massif of the domain of Oulad Dlim "dominates affected by the Hercynian phase".
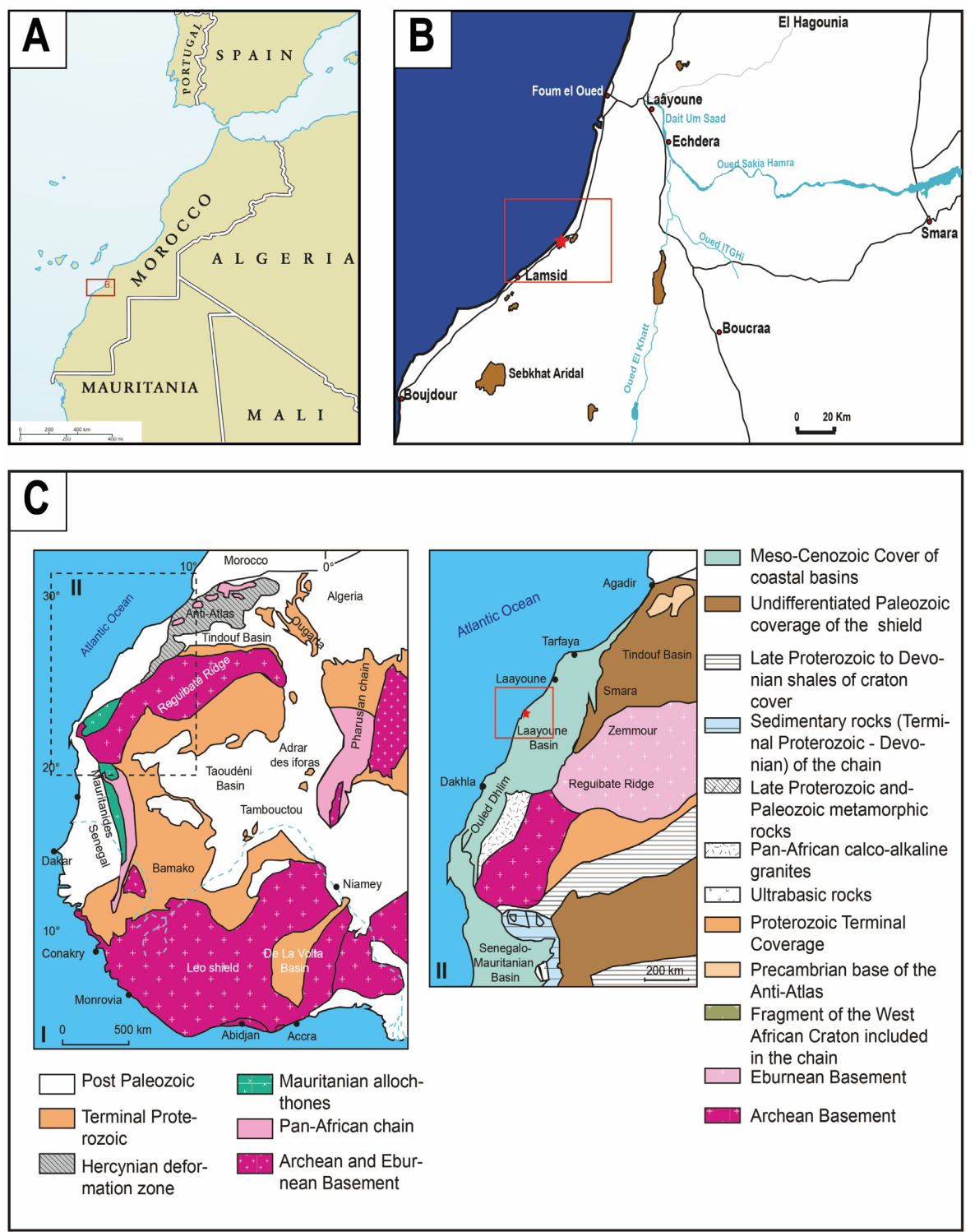

Figure 1. localization of the sector on the scale of Morocco (A) and at the level of the region of Laayoune (B). Geological setting in the studied locality (C), Tarfaya Laayoune Basin, Morocco. Adaptation from the geological map of West Africa [37]. 
The Meso-Cenozoic Tarfaya-Laayoune-Dakhla basin, a relatively tectonically stable platform since the Jurassic, is located to the NW of the Archean-Proterozoic ridge of Réguibate "NW of the West African craton" (Figure 1). Its sedimentary filling is asymmetrical, increasing from east to west, reaching a stack of about 14 kilometers [38]. The studied basin is a consequence of the opening of the central Atlantic [39]. This basin summarizes the geological history from the Trias to the Neogene at the northern borders of the West African Craton.

This basin was initially studied during oil exploration [40]. In general, the thickness of the Mesozoic series is greater than in the basins located north of the High Atlas. In the Laayoune basin, they reach over 10,000 m. The structural framework of the Layoune-Tarfaya basins, sketched by Heyman (1988), is a set of hemigrabens developed from NNW dipping listric faults, connected at a depth of about $16 \mathrm{~km}$ on a detachment fault.

To the west, the Paleozoic series are folded and form the Appalachian reliefs of the Zemmur, a little more exposed to the winds and rains of the Atlantic. In the north of the country Mechem, the Hamada Tindouf (or Draa) from a vast flat entablature, consisting mainly of limestones, which dominates the Paleozoic lands. The few wadis are directed to the center of the basin of Tindouf. To the west of the Reguibate and Zemmour extends the Atlantic plain of Tarfaya, Laayoune, Boujdour and Dakhla, whose substratum, mainly carbonated, is rich in phosphate deposits.

On the structural level, the Tarfaya-Laayoune basin boundary with the Anti-Atlas is rectilinear in a North Northeast-South Southouest direction [41]. In the South, this limit is aligned with the major accident North Northeast-South Southwest of Zemmour and two major structural directorates control the Tarfaya-Laayoune basin and its hinterland [42]:

1) East Northeast-West Southwest to North East-South West: the Atlas direction limits the Precambrian-Paleozoic to the hinterland of the Tarfaya-Laayoune Basin; this direction is materialized by the axis of the Tindouf Paleozoic basin, the Anti-Atlas chain, the Reguibat Precambrian Massive Middle Axis, the SouthAtlas Fault (East Northeast-West Southwest) and the Agadir Fault (N45 ${ }^{\circ}$ [38] [43].

2) North Northeast-South Southwest: the Meso-Cenozoic Atlantic direction coincides with the general elongation of the Tarfaya-Laayoune basin and the direction of the Zemmour fault, inherited from the Hercynian cycle [44].

3) A third $\mathrm{N} 90^{\circ}$ direction, intersecting with the coast, is apparent from the analysis of the bathymetric and gravity maps of the northwestern African margin. This family of transverse accidents segments the margin in low zones and high zones which control, from the Triassic, the distribution of the evaporite deposits [45].

\section{Material and Methods}

\subsection{Data Characteristics}

The Landsat 8 satellite rotates in a sun-synchronous, quasi-polar orbit at an alti- 
tude of $705 \mathrm{~km}$, inclined at 98.2 degrees, and performs an Earth orbit every 99 minutes. The Operational Land Imager (OLI) satellite and the Thermal Infrared Sensor (TIRS) are sensors on board the Landsat 8 satellite, which was commissioned in 2013. This satellite collects images of the Earth with a cycle of 16-day repetition (Table 1).

The OLI sensor acquires data with improved radiometric accuracy over a 12-bit dynamic range, which improves the signal-to-overall noise ratio. This translates to 4096 potential gray levels, compared to just 256 gray levels in Landsat 1-7 which has only 8-bit instruments. The OLI collects data for two new bands, a coastal/aerosol band (band 1) and a cirrus band (band 9), as well as the heritage Landsat multispectral bands [31] [32] [33].

\subsection{Methodology}

In our study, we used as data sources the geological maps of Laayoune area (1:100.000) (Figure 2) and the correspondent Landsat 8 satellite image.

As shown in the flowchart (Figure 3), we begin the study using data sources (geological map and satellite image) and a software package for atmospheric and radiometric correction, pre-processing and processing.

Then, the pre-processing step requires the stacking of the data sources necessary for the stacking of the layers, the atmospheric correction and the radiometric correction of the corrected satellite image. It is an important step in remote sensing which aims to obtain a physical parameter independent of lighting conditions and even atmospheric conditions, which allows us to use images from different eras to detect changes.

A certain number of "radiometric noises" can be present in the image due either to deficiencies of the sensors, or to problems of data transmission, or finally of interpretation (coding/decoding). Basically, these radiometric corrections are carried out directly on the image reception by reassigning codes corresponding to neighboring pixels or to defective points.

Table 1. Landsat 8 band characteristics.

\begin{tabular}{ccccc}
\hline Sensor & Band number & Band name & Wavelength $(\mu \mathrm{m})$ & Resolution $(\mathrm{m})$ \\
\hline OLI & 1 & Coastal & $0.43-0.45$ & 30 \\
OLI & 2 & Blue & $0.45-0.51$ & 30 \\
OLI & 3 & Green & $0.53-0.59$ & 30 \\
OLI & 4 & Red & $0.63-0.67$ & 30 \\
OLI & 5 & NIR & $0.85-0.88$ & 30 \\
OLI & 6 & SWIR 1 & $1.57-1.65$ & 30 \\
OLI & 7 & SWIR 2 & $2.11-2.29$ & 30 \\
OLI & 8 & Pan & $0.50-0.68$ & 15 \\
OLI & 9 & Cirrus & $1.36-1.38$ & 30 \\
\hline
\end{tabular}




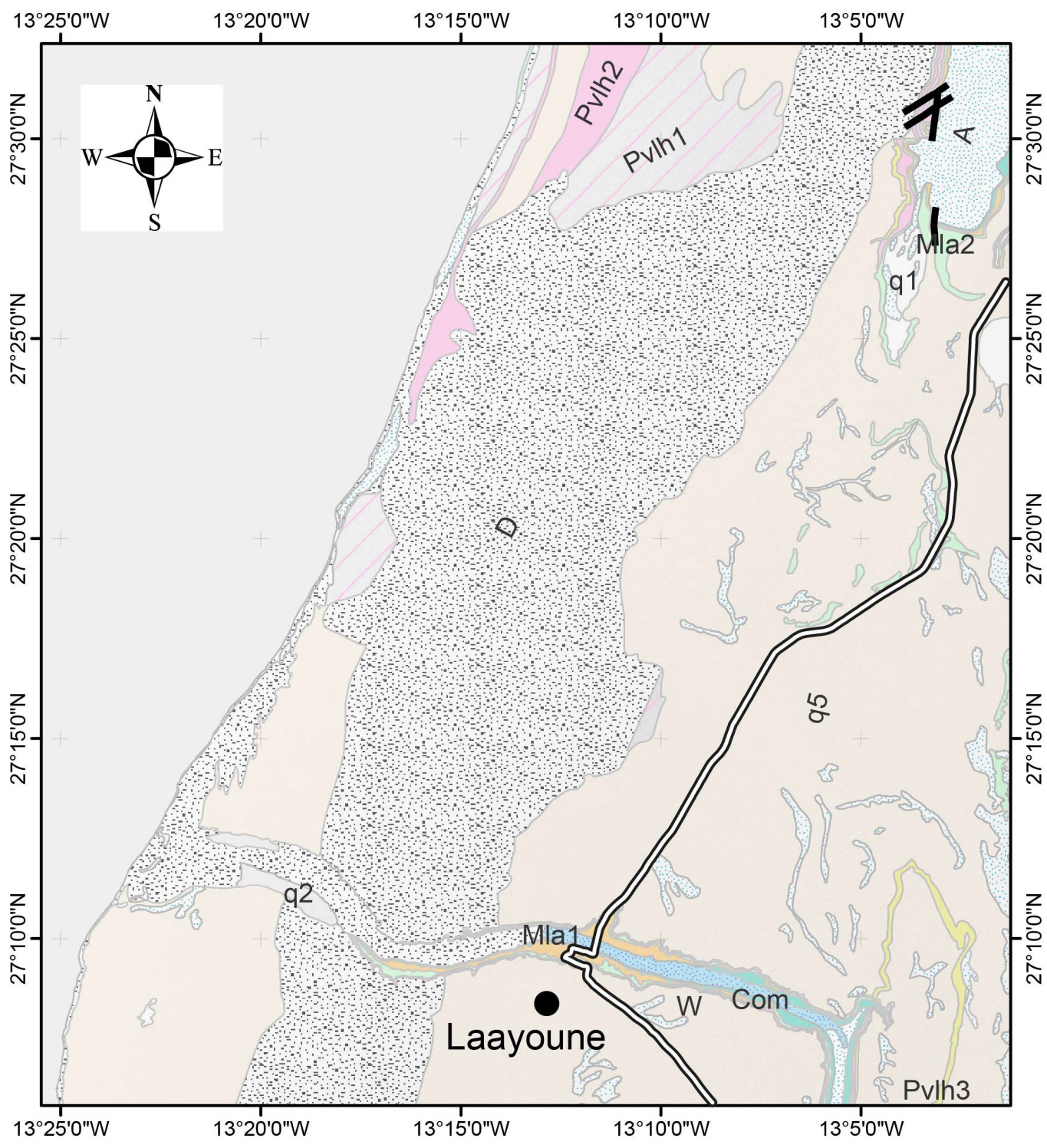

\section{Legend}

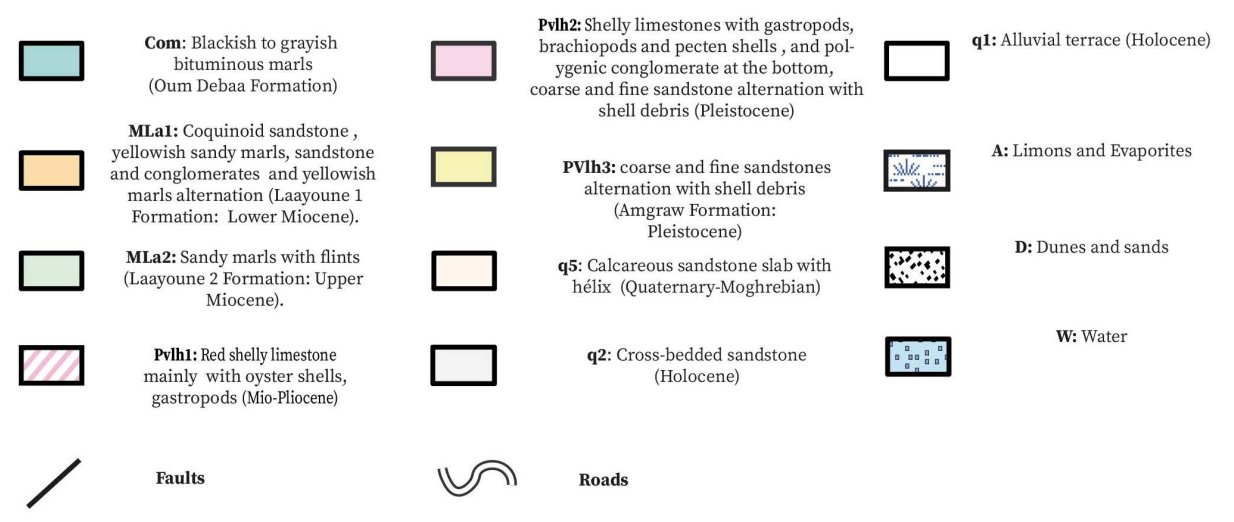

Figure 2. Geological map showing the outlines of the studied zone (Adaptation from the geological maps of LAAYOUNE area, scale: 1:100,000 [46] [47]. 


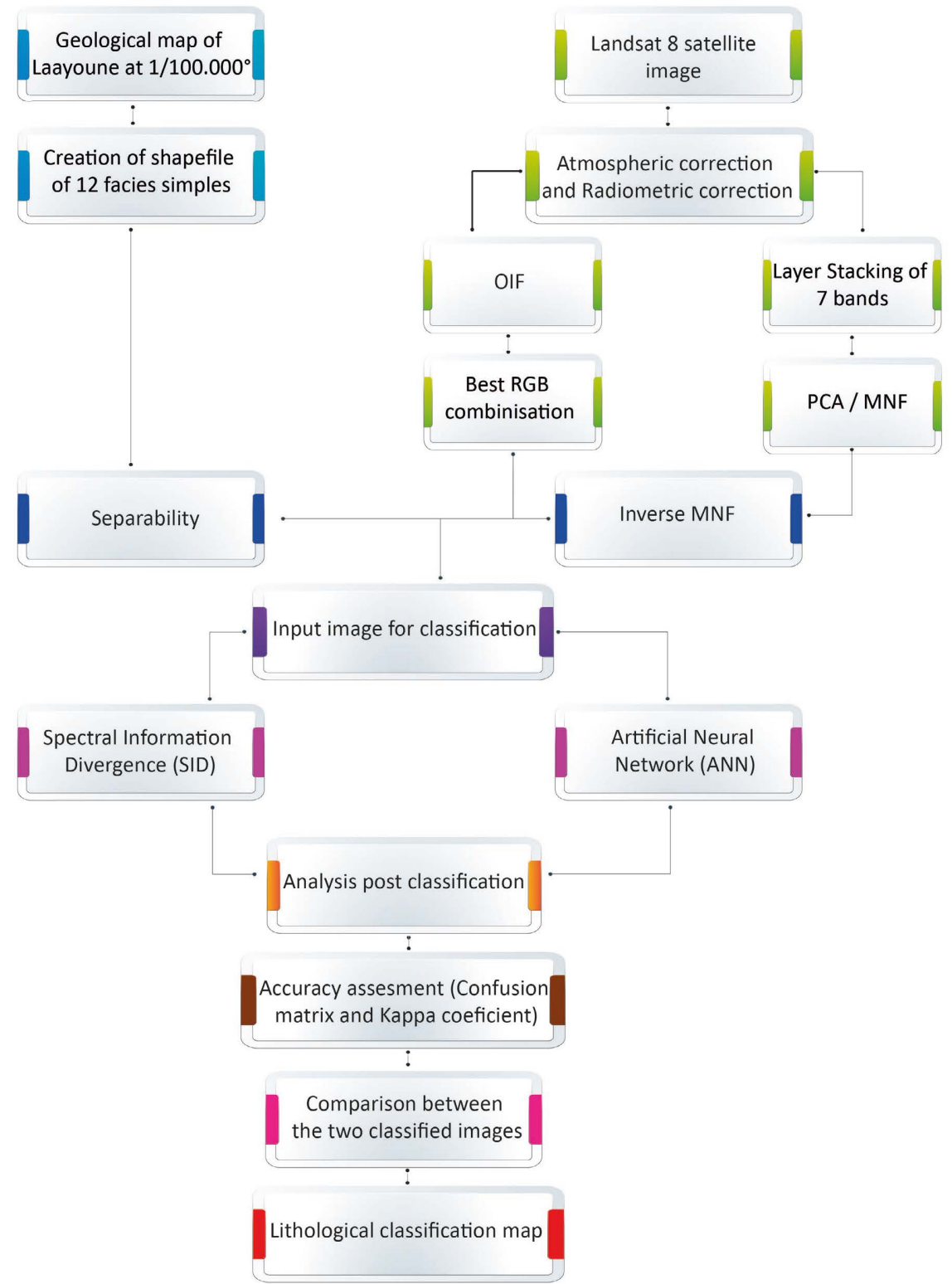

Figure 3. Methodology flowchart of the processing techniques applied for the lithological mapping based on Landasat 8 OLI data.

On the other hand, the sensors installed on board Earth observation satellites operating in the spectral range of solar emission (wavelengths of $0.24 \mu \mathrm{m}$ ) are radiometers which measure the luminance reflected by the earth + atmosphere assembly lit by the sun. In a non-cloudy atmosphere, the radiometric signal depends on the reflectance of the earth's surface but also on the effects of the atmosphere that occur during the two paths (descending, from the Sun to the surface, and ascending, from the surface to the sensor) effected by solar radiation through the atmosphere. The simple calibration of the sensor data, in luminance (absolute values measured in) or in reflectance's (relative values), therefore does not provide information on the surface but a composite signal. the objective of this correction is to extract this signal provides information independent of the 
effects of the atmosphere, which vary in time and space, and only concerning the terrestrial surface, which is the object to be studied.

\subsection{Optimal Index Factor (OIF)}

The Optimal Index Factor (OIF) is a statistical value that can be used to select the optimal combination of three bands in a satellite image with which you want to create a color composite developed by Chavez et al. (1984). It ranks the 20 three-band combinations that can be made from six TM data bands (not counting the thermal infrared band) and the optimal band combination out of all the possible 3-band combinations is the one with the greatest amount of d. "Information" (highest sum of standard deviations), with the least duplication (lowest correlation between pairs of bands). This technique is valid for any multispectral remote sensing dataset. It is based on the amount of total variance and correlation within and between various combinations of bands [48]. The algorithm used to figure the OIF for any subset of three bands is:

$$
\left(\begin{array}{c}
N \\
3
\end{array}\right)=\frac{N !}{3 ! *(N-3) !}
$$

where:

$N$ : is the total number of bands in the map list (For 3 bands, there is only 1 combination; for 4 bands, there are 4 combinations, for 5 bands, there are 10 combinations; for 6 bands there are 20 combinations; and for 7 bands, there are 35 combinations).

Then, for each combination of three bands, the OIF is calculated as:

$$
\mathrm{OIF}=\frac{S t d_{i}+\operatorname{Std}_{j}+\operatorname{Std}_{k}}{\left|\operatorname{Corr}_{i, j}\right|+\left|\operatorname{Corr}_{i, k}\right|+\left|\operatorname{Corr}_{j, k}\right|}
$$

where:

$S t d_{i}$ : standard deviation of band $i$

$S t d_{j}$ : standard deviation of band $j$

$S t d_{k}$ : standard deviation of band $k$

Corr $_{i, j}$ : correlation coefficient of band $i$ and band $j$

$\operatorname{Corr}_{i, k}$ : correlation coefficient of band $i$ and band $k$

$\operatorname{Corr}_{j, k}$ : correlation coefficient of band $j$ and band $k$

\subsection{Minimum Noise Fraction (MNF)}

Minimum noise fraction (MNF) is a powerful technique for denoising remote sensing data. This is a preparatory transformation which condenses most of the components into a few spectral bands and to classify these bands in decreasing orders of interest [49] [50]. Thus, the lower band numbers contain more spectral information and present great interest in lithological mapping [49] [51] [52] [53]. Particularly, the MNF uses a noise covariance matrix to decorrelate and resize the noise in the data and then run a pca to convert the noise-bleached data [54]. In this way, the noise is evenly distributed between the bands, which allows the method to achieve good discrimination of spectral characteristics [55]. 


\subsection{Principal Component Analysis (PCA)}

Principal component analysis (PCA) is a multivariate statistical method initiated by Pearson (1901) and widely used in the scientific community. It selects the uncorrelated linear combinations of variables such that each component successively extracts the linear combination and presents a lower variance [51].

In remote sensing, its role is to extract the desired spectral signatures by transforming a number of correlated spectral bands into a smaller number of uncorrelated spectral bands called principal components. His interest in mapping is reinforced by his ability to improve and separate certain types of spectral signatures from the background, which has led various authors to use the PCA technique [1] [2] [11] [51] [56]-[63].

\subsection{End Members Extraction}

The identification of lithological units and the classification of images using spatial remote sensing appear problematic because few images pixels display "pure" spectra [64]. Thus, the previous analyzes relating to PCA and MNF have a preponderant function for the determination of endmembers (Training Samples). Indeed, the use of Endmembers is mainly a critical step to classify the input data in the classification algorithm used [65] [66].

This approach requires a set of input endmembers that represent "pure" spectra of representative lithologies in the studied zone, where these endmembers can be extracted directly from imagery, so that all relevant materials are included that represent true surfaces and are under the same viewing and lighting conditions as all spectra in the scene. However, to limit the spectral similarity between endmembers, we used the separability of the ROI pairs to select only the most spectrally distinct. In this work, the representative endmember image spectra were derived for regions of interest (ROI) defined mainly from the existing geological map [34].

\subsection{Artificial Neural Network (ANN)}

ANNs are computer systems inspired by the neural networks that make up the human brain. Its concept is that they "learn" to do tasks from examples, generally without being programmed with task-specific rules [67] because it manages to find a solution in a non-algorithmic and unstructured way based on the adjustment of the weights connected to the network neurons [68].

For each neuron, the input value is calculated as follows [69] [70]:

$$
n e t_{i}^{n}=\sum_{j=1}^{m} \omega_{j i}^{n} \cdot O_{j}^{n-1}
$$

where:

$n e t_{i}^{n}$ : the input value of $I^{\text {th }}$ neuron in $n^{\text {th }}$ layer;

$\omega_{j i}^{n}$ correspond to the connection weight between $i^{\text {th }}$ neuron (layer) and $f^{\text {th }}$ neuron in the $(n-1)^{\text {th }}$ layer;

$O_{j}^{n-1}$ is the output of $f^{\text {th }}$ neuron in the $(n-1)^{\text {th }}$ layer; 
$m$ is the number of neurons in the $(n-1)^{\text {th }}$ layer.

In each neuron, the value calculated from the Equation (3) is transferred by an activation function. The common function for this purpose is the sigmoid function, and is given by:

$$
\operatorname{Sig}\left(n e t_{j}^{n}\right)=\frac{1}{1+\operatorname{Exp}\left(-n e t_{j}^{n}\right)}
$$

The ANN algorithm has been widely used for the classification of several sets of remote sensor data and has produced very powerful results (Jensen, 2015) compared to traditional classification methods [71] [72] [73] [74] [75]. Thus, the ANN is able to perform calculations in order to acquire, represent and calculate a map of a multivariate information space from an initial data set [76].

Image classification using ANN is performed by extracting texture features and then applying the back propagation algorithm. The typical back propagation network is characterized by input and output layers and at least one hidden one. Theoretically, there is no limit on the number of hidden layers, but there is usually only one or two. Neural Network technique uses standard back propagation for supervised learning which activates by adjusting weights in the node to minimize the difference between the activation of the exit node and the exit [77].

\subsection{Spectral Information Divergence (SID)}

SID is a spectral classification method that considers each pixel as a random variable and uses its spectral histogram to define a probability distribution [70]. For a given multispectral hyperspectral pixel vector $x=\left(x_{I} \cdots x_{L}\right)^{\mathrm{T}}$ each component $x_{I}$ is a pixel of band image $B_{I}$.

Then $x$ can be modeled as a random variable by defining an appropriate probability distribution. The component $x_{I}$ 's in $x$ are nonnegative due to the nature of radiance or reflectance. With this assumption $x_{I}$ can be normalized within the range $[0,1]$ by defining $p_{j}=\frac{x_{j}}{\sum_{I=1}^{L} x_{I}}$ so that $p=\left\{p_{I}\right\}_{I=1}^{L}$ is the desired probability vector resulting from the pixel vector $x$.

In order to further study how to use concepts arising from information theory to capture relationship and correlation between two multispectral hyperspectral pixel vectors, assume that there is another pixel vector $y=\left(y_{I}, \cdots, y_{L}\right)^{\mathrm{T}}$ with the probability distribution given by $q=\left\{q_{I}\right\}_{I=1}^{L}$ and $q_{j}=y_{j} / \sum_{I=1}^{L} y_{I}$ Using $p$ and $q$ we define Spectral Information Divergence (SID) by:

$$
\operatorname{SID}(x, y)=D(x \| y)+D(y \| x)
$$

where

$$
D(x \| y)=\sum_{I=1}^{L} p_{I} \log \left(\frac{p_{I}}{q_{I}}\right)
$$

And 


$$
D(y \| x)=\sum_{I=1}^{L} q_{I} \log \left(\frac{q_{I}}{p_{I}}\right)
$$

It should note that $D(x \| y)$ is called the relative entropy of $y$ with respect to $x$ which is also known as Kullack-Leibler information function, directed divergence or cross entropy. The SID defined by Equation (5) can be used to measure the spectral similarity between two pixel vectors $X$, and $x_{2}$.

The spectral similarity between two pixels is then measured by the difference in probabilistic behaviors between their spectra; the smaller the divergence, the more likely the pixels are to be similar [78]. Regarding methodology, the Endmember spectra used by SID can come from ASCII files or spectral libraries, or you can extract them directly from an image (as average ROI spectra) [79]; this algorithm improves the precision of the estimation of Endmember used in the optimal classification [80].

\section{Results}

The morphology of the studied area corresponds to a vast plateau (hamada) not presenting major reliefs, except for depressions (known as sebkhas) which does not rarely show most Meso-Cenozoic formations (mainly along oueds and edges of sebkhas).

Obviously, the use of remote sensing data is very valuable for the study of geological features especially in large areas with little or no in-situ data. In order to obtain better results, the Landsat 8 OLI data has been radiometrically and geometrically corrected. This pre-processing step is essential to obtain spatial and radiometric corrected images to delineate the geological units in the study area. Then, the image used requires more enhancement through the following methods (OIF, MNF and PCA).

\subsection{Enhancement Images}

First, the Optimal Index Factor (OIF) is a statistical value which help to find the optimal combination of three bands in a satellite image in order to create a color composite [10] [81]. Thus, Figure 4 shows that the band composition 6-7-8 of Landsat 8 data, represent the most optimal RGB color combination image that will be chosen for geological mapping in the study area according to the results of the OIF. Indeed, this RGB color combination represents the combination of the most information (as measured by variance) with the least duplication (as measured by correlation) and thus exhibits a noticeable color variation corresponding to large geological formations.

The MNF technique allows to segregate noise, feature extraction, spectral data reduction but also to better discriminate formation still confused at this stage. Figure 5 displays a color composite image comprising the MNF components 1, 2 and, 3 which are displayed in red, green and blue respectively. Table 2 summarizes the most influential bands in the MNF transformation, measured by eigenvectors. 


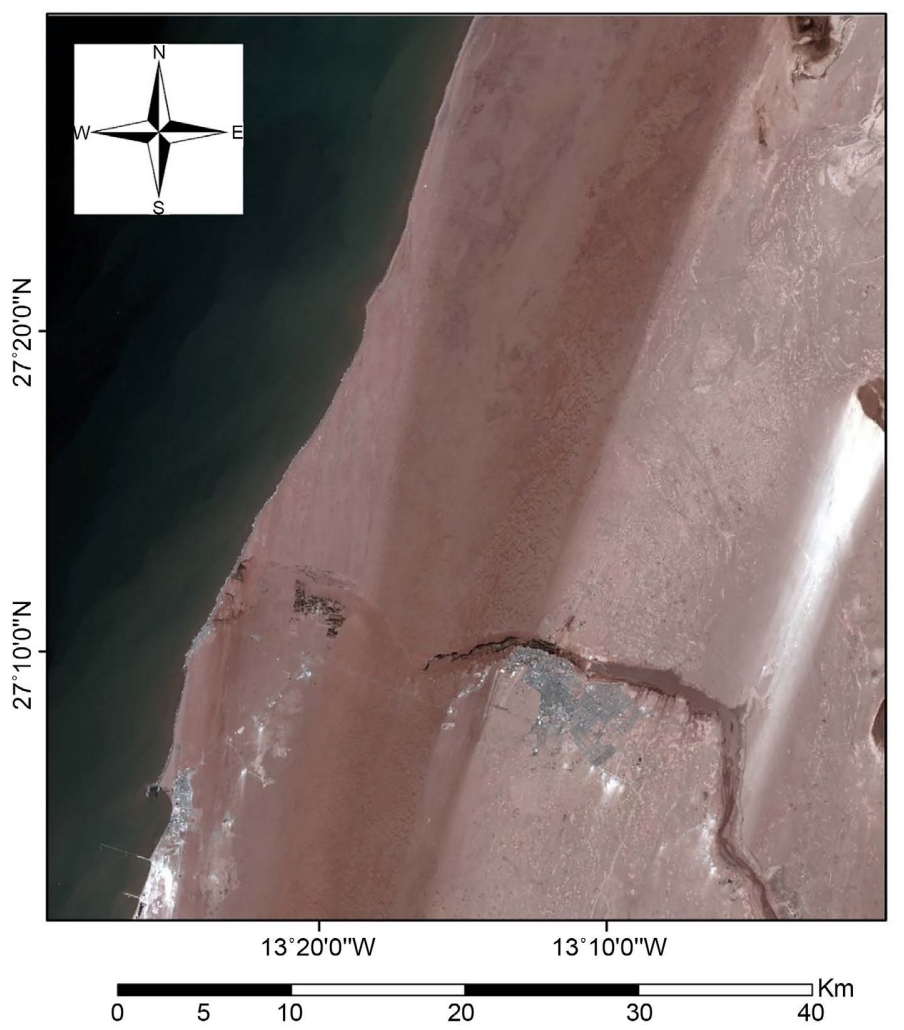

Figure 4. False colour combination with highest OIF. RGB composite of bands 6 (red), 7 (green), and 8 (blue) of Landsat 8 OLI data of the studied area.

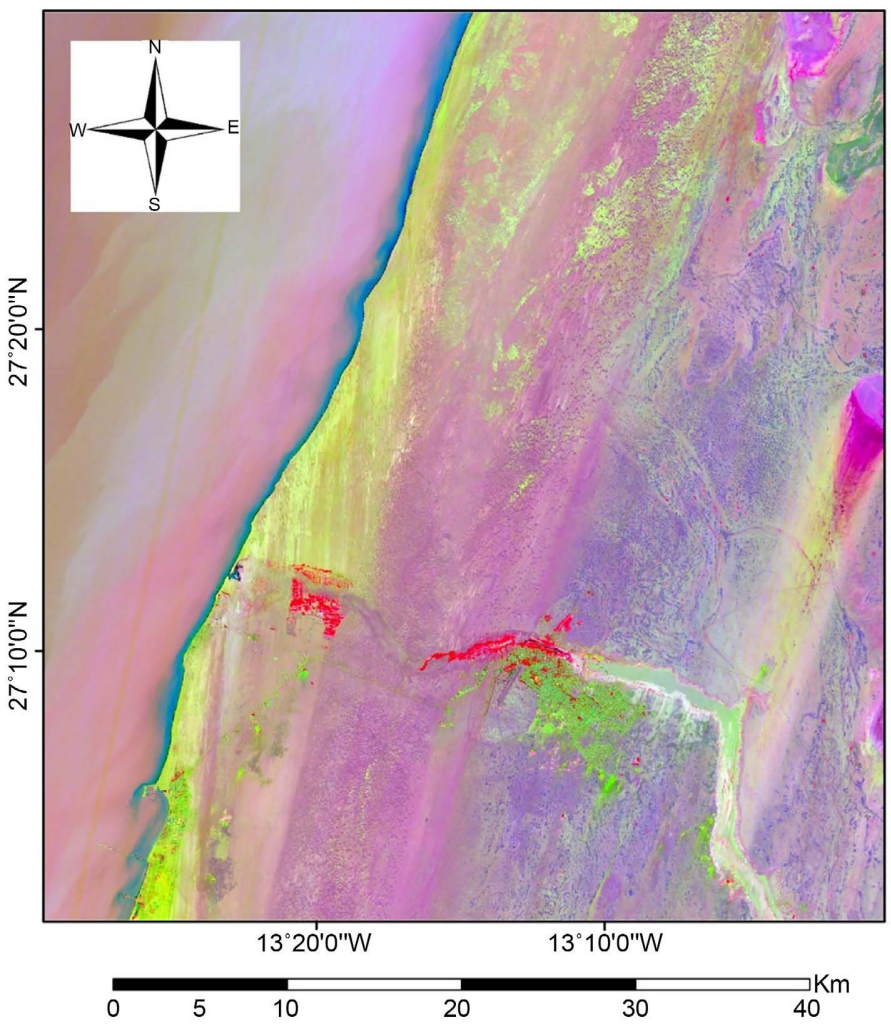

Figure 5. MNF RGB color combination (MNF 1, MNF 2, MNF 3). 
Table 2. Percentage of information contained in each MNF bands of the studied data.

\begin{tabular}{ccc}
\hline Num & Eigenvalue & percentage \\
\hline $\mathbf{1}$ & 846.91525 & 76.17522 \\
2 & 149.144175 & 13.41467 \\
$\mathbf{3}$ & 56.549253 & 5.086284 \\
$\mathbf{4}$ & 28.825196 & 2.592663 \\
$\mathbf{5}$ & 17.267562 & 1.553119 \\
$\mathbf{6}$ & 9.40914 & 0.846299 \\
7 & 3.688301 & 0.331742 \\
$\mathbf{8}$ & - & - \\
$\mathbf{9}$ & - & - \\
\hline
\end{tabular}

The PCA transform was applied to Landsat 8 OLI (Figure 6) data in order to produce uncorrelated output bands, segregate noise components, and reduce the dimensionality of the studied data. Table 3 summarizes the most influential bands in the PCA transformation, measured by eigenvectors.

The obtained results expect that the first PC represents the highest percentage of variance or eigenvalue and the last PC represents lower variance; this is computed by the presence of noise in the original spectral bands of the Landsat $8 \mathrm{da}$ ta.

Thus, more colorful color composite images are produced using PCA instead of the spectral color composite images because the spectral bands are not correlated (Figure 6 shows PCA bands 3, 1 and 2 in RGB for the study area). Thus, the structural information is well presented in the Landsat 8 image and is ready for lithological classification.

Before starting the lithological classification step, the extraction of endmembers helps to be near of the surface reality as much as possible. In this work, we chose first to study several typical cross-sections (along Oued Saquia Hamra and Sebkha Oum Debaa) and the geological map at a scale 1/100,000 [34]; at the same level, a visual interpretation on the enhanced images supported by the spectral profile of the pixels from the best OIF image.

On the other hand, to attenuate the spectral similarity between endmembers, we used the separability of the ROI pairs to select only the most spectrally distinct. In this study, and after several attempts to collect the ROIs covering the same facies on all the enhanced images (PCA and MNF), we opted for a separability threshold of 2 so that the ROI pairs are acceptable.

\subsection{SID}

Due to the lithological diversity down to the pixel, this type of classification, based on outcrop spectra, was not very satisfactory. Figure 7 shows the resulting image. Indeed, examination of the image reveals large unclassified areas and a large disparity with the geological map. 
For example, this classification does not allow to detect the large dune formation which is cut horizontally by the Oued Saquia Hamra and it replaces it by the Amgraw formation (PVlh3) and the bituminous Upper Cretaceous formation (Com). In the outcrop, the bituminous formations appear only along the Wadi and the deep sebkhas. Also, this classification does not distinguish between water and alluvial land.

Basically, the comparison of this classification with the geological map shows that the SID classification does not present a great coherence with the reality on the ground despite having presented good results in other works [82] [83] [84].

Table 3. Percentage of information contained in each PCA bands of the studied data.

\begin{tabular}{ccc}
\hline Num & Eigenvalue & percentage \\
\hline 1 & 6.61782 & 94.5403127 \\
2 & 0.353199 & 5.04570144 \\
3 & 0.016273 & 0.23247149 \\
4 & 0.009249 & 0.13212861 \\
5 & 0.00195 & 0.02785715 \\
6 & 0.001141 & 0.0163 \\
7 & 0.000366 & 0.00522857 \\
8 & - & - \\
9 & - & - \\
\hline
\end{tabular}

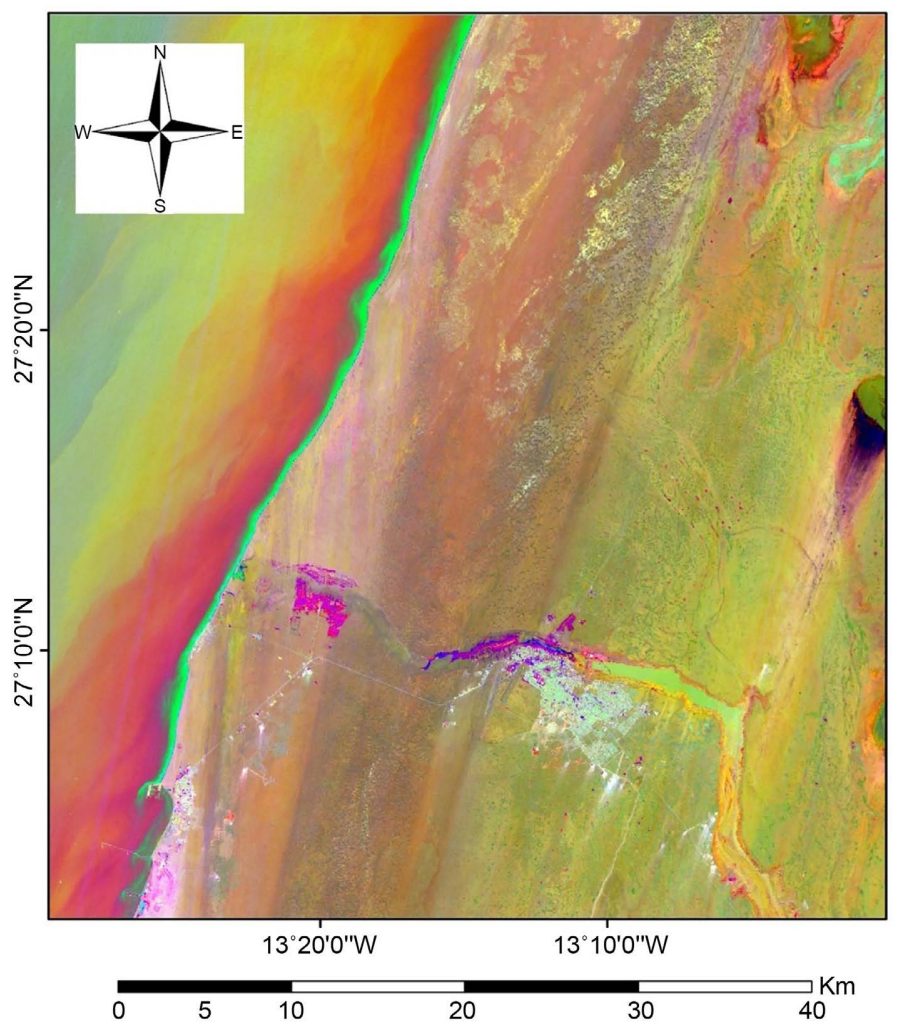

Figure 6. PCA RGB color combination (PCA1, PCA2, PCA3). 


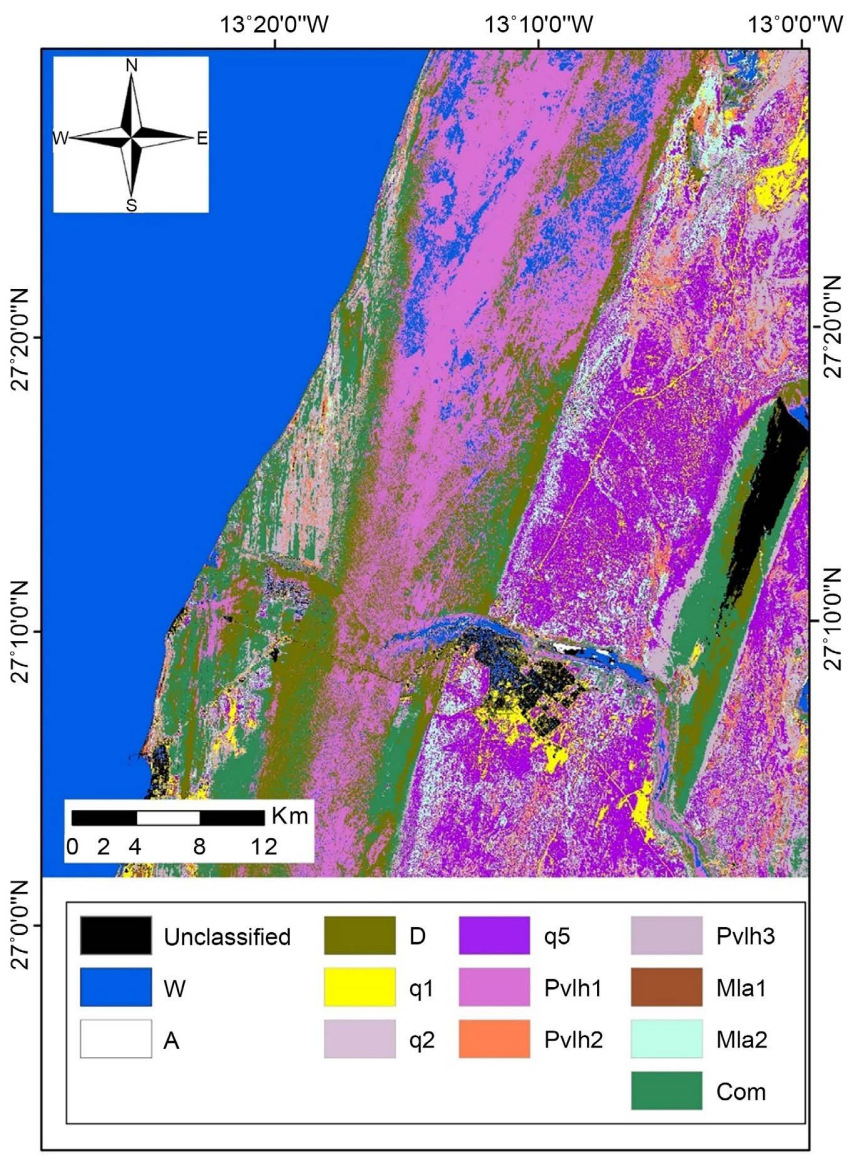

Figure 7. Classification map obtained by Spectral Information Divergence method (SID).

Quantitatively, the validation test confirms these remarks and findings and during which the accuracy assessment is $49.6144 \%$ and the Kappa coefficient does not exceed 0.4398 . Probably, the high lithological diversity was not very adequate because of the pixel resolution of the used image.

\subsection{ANN}

Unlike the SID classification, the supervised classification ANN has presented very adequate results (Figure 8) and an almost perfect correlation with the geological map of Laayoune where the formation was effortless recognized.

Indeed, the dune formation is well identified by this classification as well as the bituminous formations of Upper Cretaceous age which constitute minor thickness and have been plotted along the Oued Saquia Hamra and the edges of Sebkha Oum Debaa. Also, the Cenozoic formations show good similitude with the geological map: the hammada slab (q5), the Miocene sandstone formations (Mla1, Mla2...). Also, it should be noted that this classification differentiates the water zones from the alluvial surfaces.

The performance of these results is tested by the accuracy assessment. This assessment shows that the classification displays a precision equivalent to $92.56 \%$ and a Kappa coefficient of 0.9143 . 


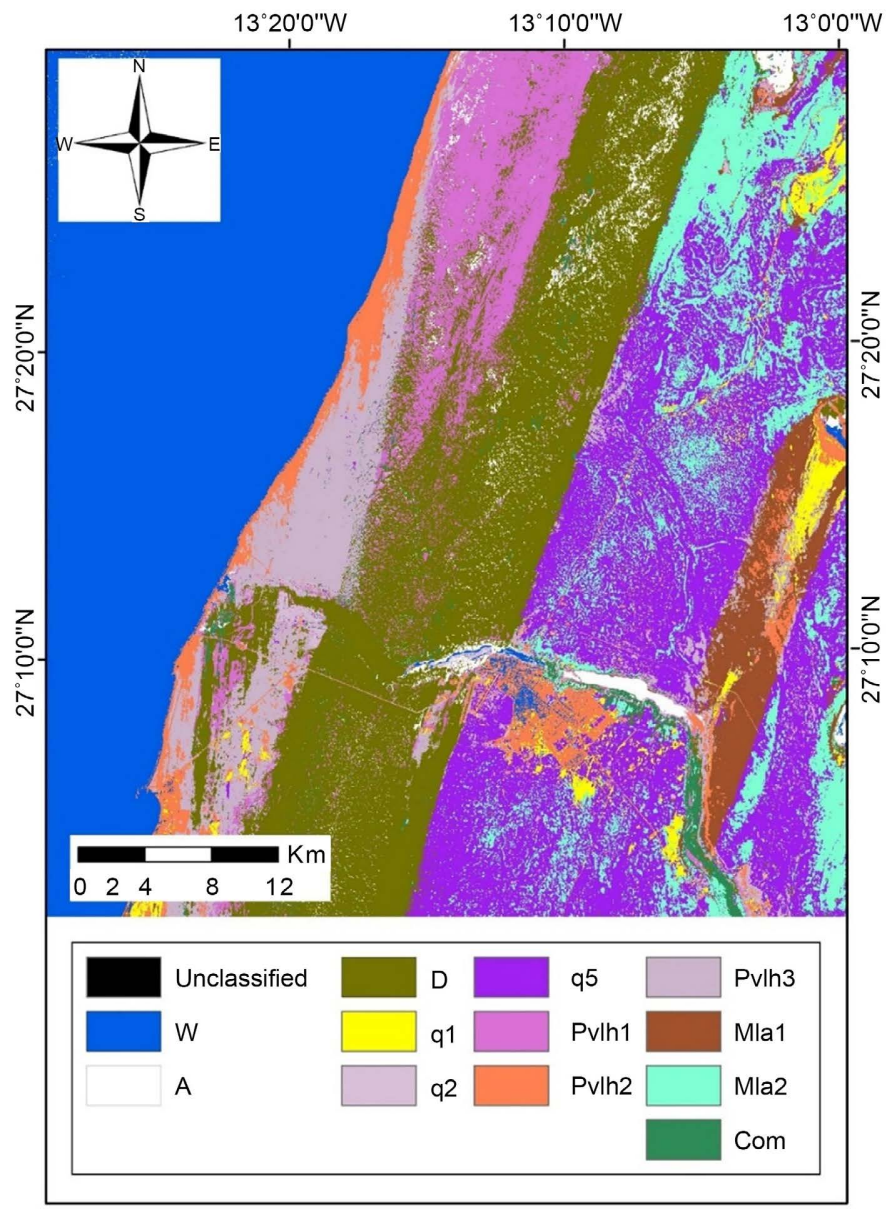

Figure 8. Classification map by the Artificial Neural Network classification.

\section{Discussion}

In order to specify which lithological classification is the most precise between the ANN and SID classifications, we used the landsat 8 OLI image which has been subjected to atmospheric and radiometric corrections. After the computation of the OIF, we obtain the highest combination of RGB bands (b6, b7, b8) which will perform a good presentation of the image data. Later, we calculated the PCA which is used to reduce the dimensionality of the satellite image and the MNF to separate the noise in the data, and to reduce the computational requirements for further processing.

The creation of ROIs is done, from the geological map of Laayoune, to supervise over the different facies in order to use it in the two classifications, then we calculate the parability which has values close to 2 that it is principal that we are correctly on the best way in our study.

After performing the two classifications: ANN and SID, the results, based on the overall precision and the confusion matrix, obtained showed that the ANN has the highest overall precision of $92.56 \%$ with a Kappa coefficient of 0.9143 (Figure 9). By ANN, the overlay of this classification image with the geological 
map shows great similarity between the classes and geological formations on the map and allows to have a greater precision in the lithofacies classification and

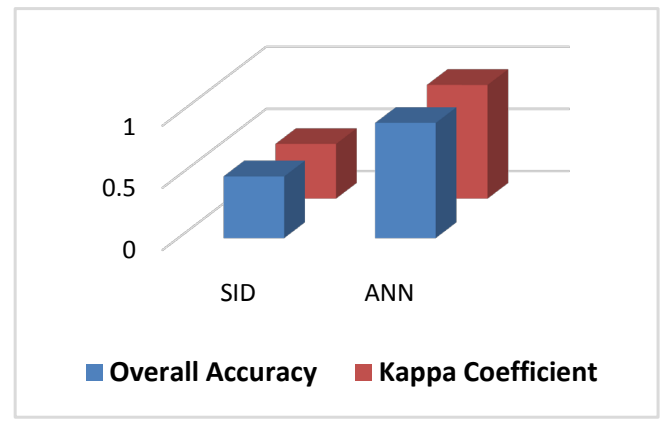

Figure 9. Accuracy assessment of the studied classifications (SID and ANN).

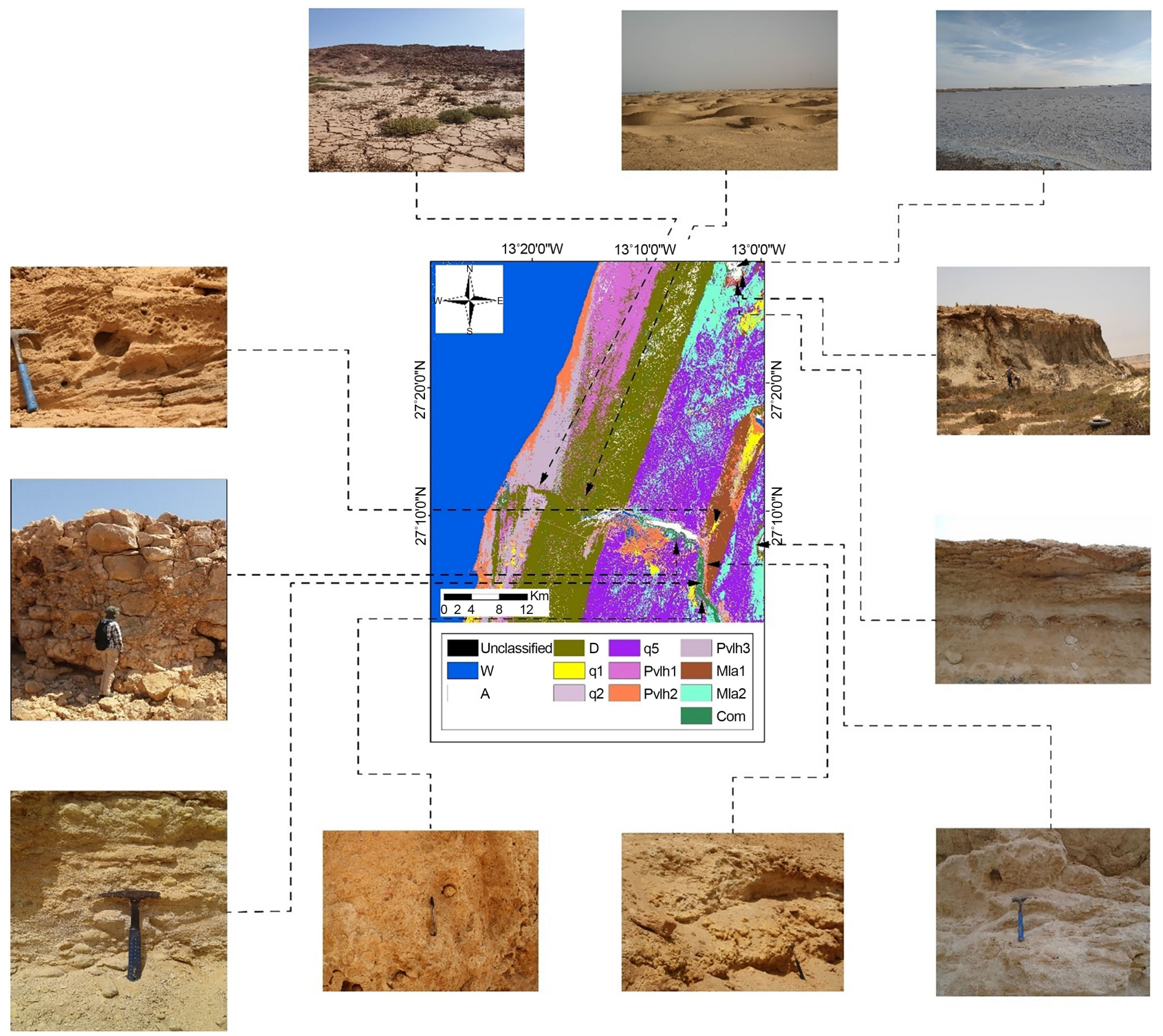

Figure 10. Qualitative validation with samples used with the ANN image. 
presents a good contribution to the spectral analysis based on the study. Definitely, adding in situ measurements of the spectral characteristics of the typical formations of the region, the Landsat 8 images could present results with more precision in the classification of the facies.

On the qualitative level, the validation of the results of the ANN classification was endorsed with outcrop images (Figure 10) with GPS position showing the land reality and the concordance with the ANN classification. Allegedly, the ANN classification shows excellent results in these very particular morphological conditions dominated by flat terrain and sand migration which hinder the visualization of satellite images.

\section{Conclusions}

The present study was carried around the Meso-Cenozoic Tarfaya-Laayoune basin (Saharian domain, Morocco). The studied area represents an arid region which corresponds to a vast plateau (hamada) not presenting major reliefs, except for depressions (known as sebkhas) which does not rarely show most $\mathrm{Me}$ so-Cenozoic formations (mainly along oueds and edges of sebkhas).

In this work, we have examined two methods of classification (ANN and SID) and compared them with the current map using an entire image processing process starting with atmospheric and radiometric correction, the georeferencing of the image and the geological map then performing the OIF, PCA, MNF calculations and creating the ROIs on which the separability calculation was performed.

After the creation of classifications input, the results were confirmed with the calculation of the confusion matrix and the Kappa index, which inform that the ANN classification is the most accurate method with an overall accuracy percentage of $92.56 \%$ and kappa index of 0.9143 .

To conclude, the remote sensing processing on Landsat 8 OLI data can allow better precision in the lithofacies classification, and it gives geologists a very good opportunity to improve their investigations in areas of difficult access. This will be a major contribution to the spectral analysis based on the study. Indeed, with a good improvement of these images by the multiple methods currently available and an adapted classification (ANN for our case) one can easily draw up a very precise lithofacies map.

\section{Conflicts of Interest}

The authors declare no conflicts of interest regarding the publication of this paper.

\section{References}

[1] Massironi, M., Bertoldi, L., Calafa, P., Visonà, D., Bistacchi, A., Giardino, C., et al. (2008) Interpretation and Processing of ASTER Data for Geological Mapping and Granitoids Detection in the Saghro Massif (Eastern Anti-Atlas, Morocco). Geosphere, 4, 736-759. https://doi.org/10.1130/GES00161.1 
[2] Amer, R., Kusky, T. and Ghulam, A. (2010) Lithological Mapping in the Central Eastern Desert of Egypt Using ASTER Data. Journal of African Earth Sciences, 56, 75-82. https://doi.org/10.1016/j.jafrearsci.2009.06.004

[3] Li, P. and Song, B. (2016) Lithological Mapping from Hyperspectral Imagery Using Extended One-Class Kernel Sparse Representation. International Geoscience and Remote Sensing Symposium, Beijing, 10-15 July 2016, 5426-5429. https://doi.org/10.1109/IGARSS.2016.7730413

[4] Fal, S., Maanan, M., Baidder, L. and Rhinane, H. (2019) The Contribution of Sentinel-2 Satellite Images for Geological Mapping in the South of Tafilalet Basin (Eastern Anti-Atlas, Morocco). The International Archives of the Photogrammetry, Remote Sensing and Spatial Information Sciences, 42, 75-82.

https://doi.org/10.5194/isprs-archives-XLII-4-W12-75-2019

[5] Kuhn, S., Cracknell, M.J. and Reading, A.M. (2019) Lithological Mapping in the Central African Copper Belt Using Random Forests and Clustering: Strategies for Optimised Results. Ore Geology Reviews, 112, Article ID: 103015. https://doi.org/10.1016/j.oregeorev.2019.103015

[6] Salati, S., Van Ruitenbeek, F.J.A., Van der Meer, F.D., Tangestani, M.H. and Van der Werff, H. (2011) Lithological Mapping and Fuzzy Set Theory: Automated Extraction of Lithological Boundary from ASTER Imagery by Template Matching and Spatial Accuracy Assessment. The International Journal of Applied Earth Observation and Geoinformation, 13, 753-765. https://doi.org/10.1016/j.jag.2011.05.004

[7] Omran, A., Hahn, M., Hochschild, V., El-Rayes, A. and Geriesh, M. (2012) Lithological Mapping of Dahab Basin, South Sinai, Egypt, Using ASTER Data. Photogrammetrie, Fernerkundung, Geoinformation, 2012, 711-726. https://doi.org/10.1127/1432-8364/2012/0151

[8] Jiang, M., Lin, Y. and Huang, Z. (2013) Lithological Mapping in the Eastern Section of Gangdise, Tibet Using ASTER and Field Spectroscopy Data. International Geoscience and Remote Sensing Symposium, Melbourne, 21-26 July 2013, 2935-2938. https://doi.org/10.1109/IGARSS.2013.6723440

[9] El Janati, M., Soulaimani, A., Admou, H., Youbi, N., Hafid, A. and Hefferan, K.P. (2014) Application of ASTER Remote Sensing Data to Geological Mapping of Basement Domains in Arid Regions: A Case Study from the Central Anti-Atlas, Iguerda Inlier, Morocco. Arabian Journal of Geosciences, 7, 2407-2422.

https://doi.org/10.1007/s12517-013-0945-y

[10] Pournamdari, M., Hashim, M. and Pour, A.B. (2014) Spectral Transformation of ASTER and Landsat TM Bands for Lithological Mapping of Soghan Ophiolite Complex, South Iran. Advances in Space Research, 54, 694-709. https://doi.org/10.1016/j.asr.2014.04.022

[11] Adiri, Z., Harti, A., Jellouli, A., Maacha, L. and Bachaoui, E.M. (2016) Lithological Mapping Using Landsat 8 OLI and Terra ASTER Multispectral Data in the Bas Drâa Inlier, Moroccan Anti Atlas. Journal of Applied Remote Sensing, 10, Article ID: 016005. https://doi.org/10.1117/1.JRS.10.016005

[12] Amusuk, D.J., Hashim, M., Pour, A.B. and Musa, S.I. (2016) Utilization of Landsat-8 Data for Lithological Mapping of Basement Rocks of Plateau State North Central Nigeria. The International Archives of the Photogrammetry, Remote Sensing and Spatial Information Sciences, 42, 335-337. https://doi.org/10.5194/isprs-archives-XLII-4-W1-335-2016

[13] Rani, N., Mandla, V.R. and Singh, T. (2016) Performance of Image Classification on Hyperspectral Imagery for Lithological Mapping. Journal of the Geological Society of India, 88, 440-448. https://doi.org/10.1007/s12594-016-0507-5 
[14] Al-Nahmi, F., Saddiqi, O., Hilali, A., Rhinane, H., Baidder, L., El Arabi, H., et al. (2017) Application of Remote Sensing in Geological Mapping, Case Study Al Maghrabah Area-Hajjah Region, Yemen. ISPRS Annals of the Photogrammetry, Remote Sensing and Spatial Information Sciences, 4, 63-71. https://doi.org/10.5194/isprs-annals-IV-4-W4-63-2017

[15] Eslami, A., Ghaderi, M., Rajendran, S., Pour, A.B. and Hashim, M. (2015) Integration of ASTER and Landsat TM Remote Sensing Data for Chromite Prospecting and Lithological Mapping in Neyriz Ophiolite Zone, South Iran. Resource Geology, 65, 375-388. https://doi.org/10.1111/rge.12076

[16] Beiranvand Pour, A. and Hashim, M. (2015) Integration of PALSAR and ASTER Satellite Data for Geological Mapping in Tropics. ISPRS Annals of the Photogrammetry, Remote Sensing and Spatial Information Sciences, 2, 105-109. https://doi.org/10.5194/isprsannals-II-2-W2-105-2015

[17] Ge, W., Cheng, Q., Tang, Y., Jing, L. and Gao, C. (2018) Lithological Classification Using Sentinel-2A Data in the Shibanjing Ophiolite Complex in Inner Mongolia, China. Remote Sensing, 10, 638. https://doi.org/10.3390/rs10040638

[18] MacMillan, R.A., Moon, D.E., Coupé, R.A. and Phillips, N. (2010) Predictive Ecosystem Mapping (PEM) for 8.2 Million ha of Forestland, British Columbia, Canada. In: Boettinger, J.L., et al., Eds., Digital Soil Mapping. Bridging Research, Environmental Application, and Operation, Progress in Soil Science, Springer, Berlin, 335-354. https://doi.org/10.1007/978-90-481-8863-5_27

[19] Moonjun, R., Farshad, A., Shrestha, D.P. and Vaiphasa, C. (2010) Artificial Neural Network and Decision Tree in Predictive Soil Mapping of Hoi Num Rin Sub-Watershed, Thailand. In: Boettinger, J.L., Howell, D.W., Moore, A.C., Hartemink, A.E. and Kienast-Brown, S., Eds., Digital Soil Mapping, Springer Science + Business Media B.V., New York, 151-164. https://doi.org/10.1007/978-90-481-8863-5_13

[20] Rigol-Sanchez, J.P., Chica-Olmo, M. and Abarca-Hernandez, F. (2010) Artificial Neural Networks as a Tool for Mineral Potential Mapping with GIS. International Journal of Remote Sensing, 24, 1151-1156. https://doi.org/10.1080/0143116021000031791

[21] Ultsch, A. (2003) Self Organizing Neural Networks Perform Different from Statistical k-Means Clustering.

[22] Gürsoy, Ö. and Kaya, Ş. (2017) Detecting of Lithological Units by Using Terrestrial Spectral Data and Remote Sensing Image. Journal of the Indian Society of Remote Sensing, 45, 259-269. https://doi.org/10.1007/s12524-016-0586-1

[23] Pal, M., Rasmussen, T. and Porwal, A. (2020) Optimized Lithological Mapping from Multispectral and Hyperspectral Remote Sensing Images Using Fused Multi-Classifiers. Remote Sensing, 12, 177. https://doi.org/10.3390/rs12010177

[24] Traore, M., Takodjou Wambo, J.D., Ndepete, C.P., Tekin, S., Pour, A.B. and Muslim, A.M. (2020) Lithological and Alteration Mineral Mapping for Alluvial Gold Exploration in the South East of Birao Area, Central African Republic Using Landsat-8 Operational Land Imager (OLI) Data. Journal of African Earth Sciences, 170, Article ID: 103933. https://doi.org/10.1016/j.jafrearsci.2020.103933

[25] Vincheh, Z.H., Arfania, R., Vincheh, Z.H. and Arfania, R. (2017) Lithological Mapping from OLI and ASTER Multispectral Data Using Matched Filtering and Spectral Analogues Techniques in the Pasab-e-Bala Area, Central Iran. Open Journal of Geology, 7, 1494-1508. https://doi.org/10.4236/ojg.2017.710100

[26] Bentahar, I. and Raji, M. (2021) Comparison of Landsat OLI, ASTER, and Sentinel 2A Data in Lithological Mapping: A Case Study of Rich Area (Central High Atlas, 
Morocco). Advances in Space Research, 67, 945-963.

https://doi.org/10.1016/j.asr.2020.10.037

[27] Kumar, C., Chatterjee, S., Oommen, T. and Guha, A. (2020) Automated Lithological Mapping by Integrating Spectral Enhancement Techniques and Machine Learning Algorithms Using AVIRIS-NG Hyperspectral Data in Gold-Bearing Granite-Greenstone Rocks in Hutti, India. The International Journal of Applied Earth Observation and Geoinformation, 86, Article ID: 102006.

https://doi.org/10.1016/j.jag.2019.102006

[28] Xie, M., Zhang, Q., Chen, S. and Zha, F. (2015) A Lithological Classification Method from Fully Polarimetric SAR Data Using Cloude-Pottier Decomposition and SVM. AOPC 2015 Optical and Optoelectronic Sensing and Imaging Technology, Vol. 9674, Article ID: 967405. https://doi.org/10.1117/12.2196856

[29] Ye, B., Tian, S., Ge, J. and Sun, Y. (2017) Assessment of WorldView-3 Data for Lithological Mapping. Remote Sensing, 9, 1132. https://doi.org/10.3390/rs9111132

[30] Roy, P.S., Behera, M.D., Murthy, M.S.R., Roy, A., Singh, S., Kushwaha, S.P.S., et al. (2015) New Vegetation Type Map of India Prepared Using Satellite Remote Sensing: Comparison with Global Vegetation Maps and Utilities. The International Journal of Applied Earth Observation and Geoinformation, 39, 142-159. https://doi.org/10.1016/j.jag.2015.03.003

[31] Campbel, B.A. (2002) Radar Remote Sensing of Planetary Surfaces. Cambridge University Press, Cambridge.

[32] Boettinger, J.L., Ramsey, R.D., Bodily, J.M., Cole, N.J., Kienast-Brown, S., Nield, S.J., et al. (2008) Landsat Spectral Data for Digital Soil Mapping. In: Hartemink, A.E., McBratney, A. and de Lourdes Mendonça-Santos, M., Eds., Digital Soil Mapping with Limited Data, Springer, Berlin, 193-202.

https://doi.org/10.1007/978-1-4020-8592-5_16

[33] Chen, X. and Campagna, D. (2009) Remote Sensing of Geology. In: Warner, T.A., Nellis, M.D. and Foody, G.M., Eds., The SAGE Handbook of Remote Sensing, SAGE, London, 328.

[34] Rjimati, E., Michard, A. and Saddiqi, O. (2011) Anti-Atlas occidetal et provinces sahariennes. Notes mémoires du Serv. Géologique No. 561, 1-95.

[35] Sauermann, G., Rognon, P., Poliakov, A. and Herrmann, H.J. (2000) The Shape of the Barchan Dunes of Southern Morocco. Geomorphology, 36, 47-62. https://doi.org/10.1016/S0169-555X(00)00047-7

[36] Rjimati, E. and Zemmouri, A. (2009) Carte géologique du Maroc au 1/100,000Feuille de Laâyoune-NG 28-XXIII-2-Notice explicative. Notes Mémoires Du Serv Géologique $\mathrm{N}^{\circ} 492$ Bis.

[37] Piqué, A., Soulaimani, A. and Hoepffner, C. (2007) Géologie du Maroc, Geode.

[38] Ranke, U., von Rad, U. and Wissmann, G. (1982) Stratigraphy, Facies and Tectonic Development of the On- and Offshore Aaiun-Tarfaya Basin-A Review. In: Geology of the Northwest African Continental Margin, Springer, Berlin, 86-105. https://doi.org/10.1007/978-3-642-68409-8_6

[39] Labails, C. (2007) La marge sud-marocaine et les premières phases d'ouverture de l'océan Atlantique Central.

[40] Heyman, M.A.W. (1989) Tectonic and Depositional History of the Moroccan Continental Margin. Chapter 21: European-African Margins. Extensional Tectonics Stratigraphy. North Atl. Margins, Vol. 156, AAPG Special Volumes, 323-340. https://doi.org/10.1306/M46497C21

[41] Choubert, G., Faure-Muret, A. and Hottinger, L. (1966) Apercu geologique du bas- 
sin cotier de Tarfaya.

[42] El Khatib, J. (1995) Etude structurale et stratigraphique d'un segment de la marge continentale atlantique sud-marocaine: Le bassin de tarfaya-laayoune. Nice.

[43] Hinz, K., Dostmann, H. and Fritsch, J. (1982) The Continental Margin of Morocco: Seismic Sequences, Structural Elements and Geological Development. In: Geology of the Northwest African Continental Margin, Springer, Berlin, 34-60. https://doi.org/10.1007/978-3-642-68409-8_3

[44] Lindner, A. and Querol, R. (1971) Mapa geologico del Sahara español 1: 200,000.

[45] El Khatib, J., El Foughali, A., Ruellan, E. and El Morabet, A. (1996) Evolution post-rift des secteurs NE et SW du bassin Tarfaya-Laâyoune. Mines, Géologie et Énergie, 57-72.

[46] Rjimati, E., Id Sahara, M., Amzahrou, M., Essalmani, B., Mustaphi, H. and Zemmouri, A. (2002) Carte géologique Tarfaya, 1/100000.

[47] Rjimati, E., Id Sahara, M., Amzahrou, M., Essalmani, B., Mustaphi, H., Zemmouri, A., et al. (2002) Carte Géologique Sebkhat Oum Deba, 1/100000.

[48] Jensen, J. (2015) Digital Change Detection, Introductory Digital Image Processing: A Remote Sensing Perspective. Pearson Prentice Hall, New York.

[49] Boardman, J., Krusce, F. and Green, O. (1995) Mapping Target Signatures via Partial Unmixing of Aviris Data.

[50] Wahi, M., Taj-eddine, K. and Laftouhi, N. (2013) ASTER VNIR \& SWIR Band Enhancement for Lithological Mapping-A Case Study of the Azegour Area (Western High Atlas, Morocco). ASTER, 3, 33-45.

[51] Pour, A.B. and Hashim, M. (2011) Identification of Hydrothermal Alteration Minerals for Exploring of Porphyry Copper Deposit Using ASTER Data SE Iran. Journal of Asian Earth Sciences, 42, 1309-1323. https://doi.org/10.1016/j.jseaes.2011.07.017

[52] Bjorgan, A. and Randeberg, L.L. (2015) Real-Time Noise Removal for Line-Scanning Hyperspectral Devices Using a Minimum Noise Fraction-Based Approach. Sensors, 15, 3362-3378. https://doi.org/10.3390/s150203362

[53] Mwaniki, M.W., Agutu, N.O., Mbaka, J.G., Ngigi, T.G. and Waithaka, E.H. (2015) Landslide Scar/Soil Erodibility Mapping Using Landsat TM/ETM+ Bands 7 and 3 Normalised Difference Index: A Case Study of Central Region of Kenya. Applied Geography, 64, 108-120. https://doi.org/10.1016/j.apgeog.2015.09.009

[54] Luo, J., Li, X., Ma, R., Li, F., Duan, H., Hu, W., et al. (2016) Applying Remote Sensing Techniques to Monitoring Seasonal and Interannual Changes of Aquatic Vegetation in Taihu Lake, China. Ecological Indicators, 60, 503-513. https://doi.org/10.1016/j.ecolind.2015.07.029

[55] Gupta, S., Islam, S. and Hasan, M.M. (2018) Analysis of Impervious Land-Cover Expansion Using Remote Sensing and GIS: A Case Study of Sylhet Sadar Upazila. Applied Geography, 98, 156-165. https://doi.org/10.1016/j.apgeog.2018.07.012

[56] Gabr, S., Ghulam, A. and Kusky, T. (2010) Detecting Areas of High-Potential Gold Mineralization Using ASTER Data. Ore Geology Reviews, 38, 59-69. https://doi.org/10.1016/j.oregeorev.2010.05.007

[57] Pour, A.B. and Hashim, M. (2012) The Application of ASTER Remote Sensing Data to Porphyry Copper and Epithermal Gold Deposits. Ore Geology Reviews, 44, 1-9. https://doi.org/10.1016/j.oregeorev.2011.09.009

[58] Rowan, L.C. and Mars, J.C. (2003) Lithologic Mapping in the Mountain Pass, California Area Using Advanced Spaceborne Thermal Emission and Reflection Radiometer (ASTER) Data. Remote Sensing of Environment, 84, 350-366. 
https://doi.org/10.1016/S0034-4257(02)00127-X

[59] Ranjbar, H., Honarmand, M. and Moezifar, Z. (2004) Application of the Crosta Technique for Porphyry Copper Alteration Mapping, Using ETM+ Data in the Southern Part of the Iranian Volcanic Sedimentary Belt. Journal of Asian Earth Sciences, 24, 237-243. https://doi.org/10.1016/j.jseaes.2003.11.001

[60] Kargi, H. (2007) Principal Components Analysis for Borate Mapping. International Journal of Remote Sensing, 28, 1805-1817. https://doi.org/10.1080/01431160600905003

[61] Zhang, J. and Zhang, Y. (2007) Remote Sensing Research Issues of the National Land Use Change Program of China. ISPRS Journal of Photogrammetry and Remote Sensing, 62, 461-472. https://doi.org/10.1016/j.isprsjprs.2007.07.002

[62] Tangestani, M.H., Mazhari, N., Agar, B. and Moore, F. (2008) Evaluating Advanced Spaceborne Thermal Emission and Reflection Radiometer (ASTER) Data for Alteration Zone Enhancement in a Semi-Arid Area, Northern Shahr-e-Babak, SE Iran. International Journal of Remote Sensing, 29, 2833-2850. https://doi.org/10.1080/01431160701422239

[63] Amer, R., Kusky, T. and El Mezayen, A. (2012) Remote Sensing Detection of Gold Related Alteration Zones in Um Rus Area, Central Eastern Desert of Egypt. Advances in Space Research, 49, 121-134. https://doi.org/10.1016/j.asr.2011.09.024

[64] Settle, J.J. and Drake, N.A. (2007) Linear Mixing and the Estimation of Ground Cover Proportions. International Journal of Remote Sensing, 14, 1159-1177. https://doi.org/10.1080/01431169308904402

[65] Roth, K.L., Dennison, P.E. and Roberts, D.A. (2012) Comparing Endmember Selection Techniques for Accurate Mapping of Plant Species and Land Cover Using Imaging Spectrometer Data. Remote Sensing of Environment, 127, 139-152. https://doi.org/10.1016/j.rse.2012.08.030

[66] Veganzones, M.A. and Graña, M. (2008) Endmember Extraction Methods: A Short Review. Lecture Notes in Computer Science (Including Subseries Lecture Notes in Artificial Intelligence and Lecture Notes in Bioinformatics), 5179 LNAI, 400-407. https://doi.org/10.1007/978-3-540-85567-5_50

[67] Rosso, P.H., Ustin, S.L. and Hastings, A. (2007) Mapping Marshland Vegetation of San Francisco Bay, California, Using Hyperspectral Data. International Journal of Remote Sensing, 26, 5169-5191. https://doi.org/10.1080/01431160500218770

[68] Filippi, A., Klein, A., Dobreva, I. and Jensen, J. (2010) Self-Organizing Map-Based Applications in Remote Sensing. INTECH, London, 231-248.

https://doi.org/10.5772/9163

[69] Haykin, S. (1994) Intelligent Signal Processing. In: Advances in Signal Processing for Nondestructive Evaluation of Materials, Springer, Berlin, 1-12. https://doi.org/10.1007/978-94-011-1056-3_1

[70] Chang, C.I. (1999) Spectral Information Divergence for Hyperspectral Image Analysis. International Geoscience and Remote Sensing Symposium, Vol. 1, 509-511. https://doi.org/10.1109/IGARSS.1999.773549

[71] Jensen, J. and Cowen, D. (1999) Remote Sensing of Urban/Suburban Infrastructure and Socio-Economic Attributes. Photogrammetric Engineering and Remote Sensing, 5, 611-622.

[72] Ji, C. (2000) Land-Use Classification of Remotely Sensed Data Using Kohonen Self-Organizing Feature Map Neural Networks. Photogrammetric Engineering and Remote Sensing, 66, 1451-1460.

[73] Foody, G.M. (2007) Approaches for the Production and Evaluation of Fuzzy Land 
Cover Classifications from Remotely-Sensed Data. International Journal of Remote Sensing, 17, 1317-1340. https://doi.org/10.1080/01431169608948706

[74] Aitkenhead, M.J. and Aalders, I.H. (2011) Automating Land Cover Mapping of Scotland Using Expert System and Knowledge Integration Methods. Remote Sensing of Environment, 115, 1285-1295. https://doi.org/10.1016/j.rse.2011.01.012

[75] Santi, E., Pettinato, S., Paloscia, S., Pampaloni, P., Fontanelli, G., Crepaz, A., et al. (2014) Monitoring of Alpine Snow Using Satellite Radiometers and Artificial Neural Networks. Remote Sensing of Environment, 144, 179-186. https://doi.org/10.1016/j.rse.2014.01.012

[76] Prabu, S. and Ramakrishnan, S.S. (2010) Combined Use of Socio Economic Analysis, Remote Sensing and GIS Data for Landslide Hazard Mapping Using ANN. Journal of the Indian Society of Remote Sensing, 37, 409-421. https://doi.org/10.1007/s12524-009-0039-1

[77] Richards, J.A. (2013) Remote Sensing Digital Image Analysis: An Introduction. Springer, Berlin, 1-494. https://doi.org/10.1007/978-3-642-30062-2

[78] Khaleghi, B., Khamis, A., Karray, F.O. and Razavi, S.N. (2013) Multisensor Data Fusion: A Review of the State-of-the-Art. Information Fusion, 14, 28-44. https://doi.org/10.1016/j.inffus.2011.08.001

[79] Du, Q. and Chang, C.I. (2004) Linear Mixture Analysis-Based Compression for Hyperspectal Image Analysis. IEEE Transactions on Geoscience and Remote Sensing, 42, 875-891. https://doi.org/10.1109/TGRS.2003.816668

[80] Xu, B., Yang, X.C., Tao, W.G., Qin, Z.H., Liu, H.Q., Miao, J.M., et al. (2010) MODIS-Based Remote Sensing Monitoring of Grass Production in China. International Journal of Remote Sensing, 29, 5313-5327. https://doi.org/10.1080/01431160802036276

[81] Qaid, A. and Basavarajappa, H.T. (2008) Application of Optimum Index Factor Technique to Landsat-7 Data for Geological Mapping of North East of Hajjah, Yemen. American-Eurasian Journal of Scientific Research, 3, 84-91.

[82] Hadigheh, S.M.H. and Ranjbar, H. (2013) Lithological Mapping in the Eastern Part of the Central Iranian Volcanic Belt Using Combined ASTER and IRS Data. Journal of the Indian Society of Remote Sensing, 41, 921-931.

https://doi.org/10.1007/s12524-013-0284-1

[83] Khaleghi, M., Ranjbar, H., Shahabpour, J. and Honarmand, M. (2014) Spectral Angle Mapping, Spectral Information Divergence, and Principal Component Analysis of the ASTER SWIR Data for Exploration of Porphyry Copper Mineralization in the Sarduiyeh Area, Kerman Province, Iran. Applied Geomatics, 6, 49-58.

https://doi.org/10.1007/s12518-014-0125-0

[84] Rao, D.A. and Guha, A. (2018) Potential Utility of Spectral Angle Mapper and Spectral Information Divergence Methods for Mapping Lower Vindhyan Rocks and Their Accuracy Assessment with Respect to Conventional Lithological Map in Jharkhand, India. Journal of the Indian Society of Remote Sensing, 46, 737-747. https://doi.org/10.1007/s12524-017-0733-3 